\title{
Knowledge for Overcoming Adversity: Gender Analysis of Economic Culture in a Region in North-Western Mexico
}

\author{
Sheila Delhumeau Rivera, Melina Ortega-Pérez-Tejada \\ Faculty of Administrative and Social Sciences, Autonomous University of Baja California, Ensenada, México \\ Email: sheila@uabc.edu.mx
}

How to cite this paper: Delhumeau Rivera, S. and Ortega-Pérez-Tejada, M. (2018) Knowledge for Overcoming Adversity: Gender Analysis of Economic Culture in a Region in North-Western Mexico. Theoretical Economics Letters, 8, 1313-1331. https://doi.org/10.4236/tel.2018.87085

Received: February 8, 2018

Accepted: May 15, 2018

Published: May 18, 2018

Copyright (c) 2018 by authors and Scientific Research Publishing Inc. This work is licensed under the Creative Commons Attribution International License (CC BY 4.0).

http://creativecommons.org/licenses/by/4.0/

\begin{abstract}
The interest in economic culture, and consequently in economic and financial literacy, has become increasingly important in the context of the recent global economic crises, as it offers a vision of the set of tools that society has at its disposal in order to face them. A gender analysis contributes to identifying the specific conditions that could affect a vulnerable group of the population: women. The goal of this paper is to analyze economic culture in Baja California, a region in north-western Mexico, at the border with the United States. To that end, a survey was designed and applied to a probability sample of 345 people in this state, to understand: knowledge of daily economic and financial aspects, money management habits, shopping habits, influence of economic socialization and information regarding economic and financial topics, perception of professional education in terms of economic aspects derived from it as well as interest in receiving economic and financial education. Results suggest that the differences found in about habits, social influences and even their role as consumers, are not statistically significant; nevertheless, important differences were found in terms of the level of knowledge, the use of tools, the currency they use for savings and their economic expectations.
\end{abstract}

\section{Keywords}

Economic Culture, Economic and Financial Literacy, Gender Analysis, North-Western Mexico

\section{Introduction}

Researching the population's economic and financial culture has become increasingly important in the context of the recent global economic crises, and of the 
apparent fact that the decisions made by individual agents are sometimes at odds with the theory of rationality [1] [2]. In the last decade, several psychological factors have been detected, such as habits and attitudes, which influence decision making, together with more personal individual influences, such as: economic socialization within the family, social circles of the individuals, educational level and productive activities they perform, as well as the experiences they have had in the course of their lives [3].

Observing whether there are differences in knowledge, attitudes, influences and habits with respect to gender has also become a topic of interest within the academic community, due to the fact that several studies performed in this field. [4] has suggested that women, and especially single mothers, are a group that could be considered vulnerable due to its lag in terms of economic and financial literacy [5] [6] [7].

In Mexico, even though there are government bodies that offer support and consultancy in terms of financial education-such as the Bank for Financial Services (BANSEF) and the National Commission for the Defense of Users of Financial Services (CONDUSEF) - and in spite of the financial education programs offered by some banks to their users and to certain sectors of the Mexican population, the overall picture of economic and financial culture of the Mexican population has been a topic of insufficient study by the academic and public sectors. Even though the Population Census and the Economic Census carried out by the National Institute for Statistics, Geography and Information (INEGI) provide a certain amount of data which allows for approximation in this area, the truth remains that up until nine years ago there was no investigation or study performed on the knowledge and habits of the Mexican population in the economic and financial fields.

The first national survey on financial culture was published in 2008 and was carried out by the National Autonomous University of Mexico (UNAM), commissioned by the Banamex Financial Group. This survey interviewed heads of households, couples and/or family members between 18 and 65 years of age that could provide answers about the financial habits and customs of the group that each household belonged to.

The second national survey on financial culture focused on young people between 15 and 29 years of age, which, according to the Banamex Financial Group, represented a highly heterogeneous group in terms of opportunities and inequalities, since it contained many people who have had to leave school and find a source of income in order to survive, as well as many people with a high educational level and with no problems regarding daily expenses [8]. These young people presently make up a little over a quarter of the Mexican population; and it is they who have gone through-at the peak of their productive lives-the change in tax and labor structural reforms, the modifications to the Retirement Savings Law (and everything this leads to in terms of retirement benefits).

As regards the formal education, it was in the 2008-2009 school year that the 
Program for Economic and Financial Training was launched by the Secretary of Public Education and, at the same time, the Mexican Council for Economic and Financial Education (CMEFF) was created. These actions, as well as others carried out by financial institutions, are proof of the need for a change in the way Mexican people think of what economic and financial culture means. According to certain actors, all other aspects of a nation's daily and productive lives depend on it [8] [9] [10].

In this context, we consider it important to carry out a regional economic culture study in a north-western Mexican state:

1) In order to achieve a detailed overview based on which to suggest policies and programs focused on providing the necessary elements so that all the population can acquire this knowledge and the opportunity to develop the required skills to make better personal decisions;

2) To benefit from the positive situations and to minimize the negative impacts that the "demographic bonus" brings about in Mexico, which, like other countries in Latin America, is now in a period of reversal of the population pyramid; and,

3) To understand the regional specificities of border regions and their necessities.

This paper is organized as follows: in the first section we discuss the generalities about economic and financial literacy theory; secondly, we present the methodology followed in this research. The third section showcase the results organized by variables of study; and in the last section we comment our conclusions regarding the differences of economic behavior we found regarding women and men in Baja California, Mexico.

\section{Economic Culture and Economic and Financial Literacy}

The same way that traditional literacy allows people to decipher signs, symbols and written letters, economic and financial literacy, as a technical tool to understand economic culture, has become necessary in life, as it allows people to generate adequate knowledge, skills and attitudes which apart from granting comprehension of the functioning of the economic system they are a part of, also trains them for making decisions that allow them to use and optimize their available resources, especially in the context of a complex and extremely changing economy.

In 1993, Rawbow and Rodriguez stated that there were not enough studies regarding how individuals envision the use of money, i.e. how boys and girls in every family are being educated economically and financially, emphasizing the fact that economic socialization depends on these aspects, and it can vary greatly, depending on many factors such as social status, ethnic group or race (among others), but most of all, depending on gender (in terms of both giving and receiving this socialization) and on the status of the woman within the family, whether it is a single parent family or even whether the woman has her own 
source of income. The authors emphasize the fact that for women, money and its use represents a source of power, which allows them independence and autonomy, voice and vote in the participation in the decision making process both within the family and within society in general.

In their study on gender and economic literacy, Denegri and Palavecinos [1] state the importance of taking into account the psychological aspect of the economic behaviors, given the fact that if we consider only the "traditional" economic analysis, under the assumption of "rationality" of the human behavior, conducts such as excessive debt, impulsive and compulsive consumption lose their meaning and find no theoretical explanation to support them (or any kind of model to predict them).

The authors suggest, based on other research, that the context of the individual and the consumerist system, taking into account the means of communication (among other factors), is the one that may lead the person to experience impulses regarding consumption and resource use in a particular way, such as the will to have a particular living standard, or even the acquisition of misconceptions regarding intangible aspects like money "that cannot be seen", by means of tools like the credit card [1].

For the authors, the level of knowledge and the level of information that people have regarding economic and financial aspects are key variables to be able to observe a correct or incorrect use of money, they can make the difference between the assertive use of a loan to fulfill a need, or excessive debt. The authors found that it was women who associate the function of money with the possibility to satisfy basic needs. On the other hand, with regards to the role of government and monetary issue, they do not specify which group, but explain that there were cases when the research subjects considered that issuing currency at will be a viable solution to the nation's economic crisis.

The role that government plays within the economy is important, but so is the information and the knowledge that the people have about that role of the government, its policies and results obtained, because this knowledge is part of the way in which they envision the economic system which they are a part of, and it also has the ability to boost or discourage their active participation as economic agents and voters. As Denegri and Palavecinos put it, there are "conceptual gaps" that some people-especially the women in their study-exhibit when assigning erroneous responsibilities and charges to the figure of a government: for some people it should be more paternalistic, controlling the entire economic system, while for others it should be more active but without authoritarian interference.

In that sense, identifying for every economic actor-including the government-their corresponding responsibility, as well as establishing their correct roles, action or reaction, is part of a complex decision making scenario. This becomes more relevant when those decisions have a cost that goes beyond affecting the people making them, the result of the sum of the individual decisions can 
trigger increase or decrease the effects of a generalized economic crisis.

That is why abilities and knowledge on how to identify the sources and the language to obtain correct economic information-how to know the exchange rate when living near the border, or be aware of the fact that buying foreign products affects the local economy, as well as making basic supply and demand analyses in daily shopping, are all indispensable tools to survive in a market economy.

\section{Methodology}

The investigation carried out is quantitative; it used a questionnaire made up of 64 questions, separated into: economic knowledge, planning, income behavior, savings, expenses, attitudes and use of loans, influences and expectations for the future.

The survey was administered to 345 people: 192 women and 153 men distributed in the 5 municipalities that make up the state of Baja California, in the summer of 2014. Expecting variability in the characteristics of the surveyed population, and to facilitate the cost and process of data collection, the interviews were conducted at points of great influx of people in each city, at times when people are in transit. As there are no similar studies carried out in the area, this study is descriptive-exploratory.

\section{Description of the Sample}

In the group of the 192 female respondents, the minimum age was 13 and the maximum was 62 , while the mode was 19 years old (5.7\%). $44.8 \%$ of the women were single, $34.4 \%$ married, $13.5 \%$ in a domestic partnership, $3.6 \%$ were divorced, $2.1 \%$ widows and $1.6 \%$ were separated. $35.4 \%$ had no children, $22.9 \%$ had 2 children, $17.7 \%$ had 3,10.9\% had 4 and $4.6 \%$ had between 5 and 8 children.

Regarding economic dependents, $44.3 \%$ had none, $53.1 \%$ had between 1 and 4 dependents while $2.6 \%$ had between 5 and 7 economic dependents.

In terms of educational level, $16.7 \%$ had finished elementary school, $28.1 \%$ had graduated secondary school, $32.8 \%$ had finished high school, $3.6 \%$ had an associate's degree, $14.6 \%$ a bachelor's degree, $2.1 \%$ a postgraduate degree while $2 \%$ had no educational level. $33.3 \%$ were studying at the time of the survey.

Furthermore, 25.5\% had once studied in a private school, 13.5\% spoke English and $58.3 \%$ were employed at the moment of the survey. From that group of employed women, only $29.7 \%$ stated they had some kind of benefits. $57.1 \%$ had a full time job, $20.6 \%$ worked part time and $22.3 \%$ worked occasionally. $14.6 \%$ had never worked up to the moment of the survey (only $4.7 \%$ were underage). $14.6 \%$ had started working between the ages of 6 and 14, $41.6 \%$ between the ages of 15 and $18,21.8 \%$ between the ages of 19 and 28 while $0.5 \%$ started working and receive a wage at around 47 years old.

In the group of the 153 male respondents, the minimum age was 15 and the 
maximum 79. The mode was 21 years $(6.5 \%) .54 .2 \%$ of the men were single, $33.3 \%$ were married, $9.8 \%$ were in a domestic partnership and $2.6 \%$ divorced. $49 \%$ had no children, $46.4 \%$ had between 1 and 4 children and $4.7 \%$ had between 5 and 10 children.

In terms of levels of education, $13.7 \%$ finished elementary school, 19\% secondary school, $43.1 \%$ had finished high school, $2 \%$ had an associate's degree, $5.2 \%$ had a postgraduate degree and $2.6 \%$ had no educational level. $37.3 \%$ were studying at the time of the survey. Furthermore, $28.1 \%$ had studied in a private school at some point. $21.6 \%$ spoke English and $71.7 \%$ were employed at the moment of the survey, of which only $41.8 \%$ stated they had some kind of benefits.

$50.9 \%$ had full time jobs, $15.7 \%$ worked part time and $4.6 \%$ worked occasionally. $27.5 \%$ were retired and $0.7 \%$ stated they were looking for a job at the time of the survey, and another $0.7 \%$ stated they had more than one job (part time or occasional, etc.). $4.6 \%$ had not had to work (and receive a wage) in their life (although only $2.6 \%$ were underage). $25 \%$ had started working between the ages of 6 and 14, 68.1\% started working between the ages of 15 and 18, and 16.5\% started working between the ages of 19 and 23, which was the maximum work starting age in the group.

Regarding economic dependents, 51\% had none, $44.3 \%$ had between 1 and 4 , while $5.3 \%$ had between 5 and 10 economic dependents.

\section{Results}

\subsection{Economic Knowledge}

In the present study, seven questions were asked, considered to be fundamental to determining the knowledge regarding the economic context of the region and the country, faced with the recently implemented legislation changes. These questions were:

1) “Do you know today's exchange rate?"

2) "What do you think the exchange rate depends on?"

3) "What do you understand by inflation?"

4) "What does devaluation mean to you?"

5) "Do you know that the present VAT rate is in Baja California?"

6) "Do you know what the minimum wage in Baja California is?"

7) "Do you know the cost of a liter of gas in Baja California?"

The results of this variable were used to build an index of economic knowledge (see Table 1). Notable differences are observed between men and women starting with level 4 , where there are more men with higher levels of knowledge. The non-parametric statistical test indicates a significance level of 0.000 , which allows us to assume with a level of confidence of $95 \%$ that gender differences are basically not real for this sample.

While performing an analysis on each of the items that make up the knowledge index, significant changes were found in the following variables: knowledge of the 
Table 1. Economic knowledge index by gender.

\begin{tabular}{cccc}
\hline \multirow{2}{*}{ General Economic Knowledge Index } & \multicolumn{3}{c}{ Sample's percentage } \\
\cline { 2 - 4 } & Total & Women & Men \\
\hline 1 & $9.6 \%$ & $7.8 \%$ & $1.7 \%$ \\
2 & $15.1 \%$ & $8.7 \%$ & $6.4 \%$ \\
3 & $16.8 \%$ & $9.6 \%$ & $7.2 \%$ \\
4 & $19.4 \%$ & $12.2 \%$ & $7.2 \%$ \\
5 & $26.1 \%$ & $12.8 \%$ & $13.3 \%$ \\
6 & $8.4 \%$ & $2.6 \%$ & $5.8 \%$ \\
7 & $3.8 \%$ & $1.7 \%$ & $2.0 \%$ \\
\hline
\end{tabular}

Source: Compiled by the author based on results.

exchange rate, since even though $85 \%$ of the sample did not answer correctly, there were more women who did not know it, and of the $14 \%$ respondents who did know the answer, there were more men who did; the same happened with the VAT rate in force, the minimum wage and the gas price.

This result coincides with the findings of Rawbow \& Charness [11], where in a study performed with women students, the authors reported that many of them had extremely unreal notions and were highly uninformed regarding money, particularly regarding the cost of life. In this case, although the gas price may not be fundamental for those who do not use or own a vehicle, it is considered basic due to its influence on the price of other goods and services and therefore, staying informed regarding its changes can be a key factor in anticipating, predicting and understanding the shifts in prices of basic household provisions.

It is important to point out, regarding the VAT rate in force at the time of the survey, that the region was in full commotion and debate with respect to a recent standardization of the border VAT rate with that of the rest of the country: from $11 \%$ paid in value added tax, it was standardized to $16 \%$ paid in non-border areas. The subject in question was the main topic of conversation in the media (radio, television, internet, newspapers), signatures were being gathered from all fronts: business, education and social, to request a reversal of the measure that had already been in place for several months, but in spite of that, $49.9 \%$ of the respondents could not answer what the VAT rate in force was. Some even mentioned rates way below the original $11 \%$, before the standardization. Of that group (basically half the sample), $18.6 \%$ were men and $31.3 \%$ were women.

A similar situation occurred with the minimum wage, as there was a rumor going that there would soon be a standardization like the one of the VAT rate, although this had not occurred up to the time of the survey. Nevertheless, $93.9 \%$ of the respondents did not know what the minimum wage in force was. In fact, it was considered a "correct answer" when they mentioned "69 pesos", but of the $6.1 \%$ who did so, there were very few ( 3 people) who gave the correct amount 
(69.17 pesos). And only one of those had professional education, another was a micro entrepreneur and the last one was a factory worker. All three were men.

In the case of the other questions regarding the concepts of inflation and devaluation, it is worth mentioning that it was women who made up the group with the highest level of knowledge, but the results were not significant in terms of a gender based group comparison. It is as though most of the women in the sample had the "theoretical basis" but no "practical knowledge".

\subsection{Planning and Control}

Making a plan before an expenditure is an efficient tool to maintain control of personal finance and of the economic situation both in the short and the long term. As with any administrative process, planning is the first step in correctly identifying the needs to be met. Complementing it with budget planning and comparisons of products, services and other possible options, allows a more efficient use of one's income or budget than they would get without the control of such aspects. In this part they were asked about planning and records of the following basic aspects: savings, loans and expenses.

Despite the fact that the differences found were not significant with respect to gender, it is important to mention that there are more women who have no planning of the three basic aspects of personal finance control (see Table 2); also, even though there were more women than men who planned at least one of the three aspects, this relationship changed when dealing with two aspects, then changed once again when dealing with all three.

Relating this data to that obtained from asking whether they compare offers, brands and prices before purchasing (with data from only 161 women and 127 men in this section), it can be clearly noted that both women and men tend to be more careful with regard to planning their expenses; there are even those who compare all the aspects mentioned before making a purchase.

Furthermore, it was also observed that both groups do less planning regarding loans (only $46.6 \%$ of the women and $42.5 \%$ of the men), but more men plan their savings than women (86.6\% and $80.1 \%$ respectively), while in terms of planning expenses, the difference is minimal ( $92.9 \%$ and $92.5 \%$ in equal order). This weighting of priorities for the expenses-savings-loans planning can also be observed without separating by gender, with a distribution of $92.7 \%, 82 \%$ and $45 \%$ respectively.

Table 2. Planning by gender.

\begin{tabular}{ccccc}
\hline \multirow{2}{*}{ Gender } & \multicolumn{4}{c}{ Planning } \\
\cline { 2 - 4 } & No planning & Plans 1 aspect & Plans 2 aspects & Plans all 3 aspects \\
\hline Women & $9.0 \%$ & $7.8 \%$ & $21.8 \%$ & $16.9 \%$ \\
Men & $7.6 \%$ & $4.9 \%$ & $18.9 \%$ & $13.1 \%$ \\
Total & $16.6 \%$ & $12.8 \%$ & $40.7 \%$ & $29.9 \%$ \\
\hline
\end{tabular}

Source: Compiled by the author based on results. 
In regards to finance control which can be carried out by means of developing records of those aspects, the following was observed: $51.9 \%$ of the general sample keep no records. $11 \%$ keep records of one aspect, $18.2 \%$ keep records of two aspects and $18.8 \%$ of all three aspects. The distribution by order of priority is similar to that of planning, as only $23.8 \%$ keep records of their loans, $37.6 \%$ do so regarding savings and $43.1 \%$ keep records of their expenses.

The distributions by gender are as follows: $15.1 \%$ of women and $8.7 \%$ of men claim to keep records of loans, $21.7 \%$ of women and $15.9 \%$ of men keep records of their savings while $26.1 \%$ of women and $17.1 \%$ of men keep records of their expenses.

\subsection{Purchases and Expenses}

Purchase habits are important because they can be reflected in the level of economic and financial literacy: good habits can help save money when needing to purchase a particular item, while bad habits can generate excessive debt. A habit that can be considered positive could be comparing products, prices and offers before making a purchase.

In general, when dealing with purchases, $19.4 \%$ of respondents tends to compare prices, $15.9 \%$ compares offers and only $4.1 \%$ compares brands. $12.5 \%$ claim not to make comparisons, $14.5 \%$ compare at least 2 aspects, and $33.6 \%$ state they compare all aforementioned aspects.

With respect to unnecessary expenses (see Table 3), there are no significant differences in each of the sections that make up the set of options. They were asked if they had "had any expenses they considered unnecessary in the last month". For example, food is not considered unnecessary if it can be prepared at home, but when eating out not because of necessity but in order to treat oneself, the majority of the more economical individuals think twice before doing it.

In this section it was found that, in general, more money is spent on "social life and entertainment", with the majority of this group being made up of men. The next aspect most widely mentioned is buying food outside the household, or buying "treats" in the street, and here once again the group was made up of a majority of men; the situation changes when dealing with unnecessary expenses for "clothes, shoes and accessories": of the $19.8 \%$ of the group, $15.6 \%$ are women and only $4.2 \%$ are men. A similar phenomenon is observed with "beauty and personal care".

An index of unnecessary expenses was elaborated with these variables, and the

Table 3. Unnecessary expenses by gender.

\begin{tabular}{lccc}
\hline \multirow{2}{*}{ Gender } & \multicolumn{3}{c}{ Did you have any unnecessary expenses in the last month? } \\
\cline { 2 - 3 } & Food, restaurants or snacks & Clothes, shoes and accessories & Social life and entertainment \\
\hline Women & $12.5 \%$ & $15.6 \%$ & $10.4 \%$ \\
Men & $14.1 \%$ & $4.2 \%$ & $19.8 \%$
\end{tabular}

Source: Compiled by the author based on results. 
results show that $43.3 \%$ ( $45.3 \%$ women and $43.1 \%$ men) of the population is at level zero, which is the minimum number of points (no unnecessary expenses), $52.5 \%$ (51\% women and $54.2 \%$ men) had made at least 1 unnecessary purchase, $2.6 \%$ (2.6\% women and $2.6 \%$ men) had made 2 purchases they considered unnecessary and $0.6 \%$ ( $1 \%$ women and $0 \%$ men) had made at least 3 unnecessary purchases, this being the highest level of the sample (the scale itself could lead up to 8$)$.

This index also had no significant differences in terms of the group of women and men, but it is worth mentioning that there were only women in the highest level of unnecessary expenses had in the month before the survey.

\subsection{Loans and Debt}

One of the crucial aspects of economic culture is the adequate use and management of debt. Asking for a loan or having a credit can represent - in the face of a lack of savings at a particular moment in time - obtaining a good or service that is really necessary, even without having the money to pay for it. The adequate use of money that does not belong to us in order to purchase or satisfy needs can make a difference in some cases, and when talking about health it can even make the difference between life and death. But the incorrect use or non-payment of a loan can mean not being able to access that type of resources, and in the case of loans from a particular institution, the debt also includes payment of interest and penalty interests when the correct reimbursement is not done timely and in due form.

$0.9 \%$ of the respondents in this sample dedicate less than $10 \%$ of their income to paying debts $(0.5 \%$ women and $1.5 \%$ men), $14.5 \%$ of them dedicate between $10 \%$ and $25 \%$ of their income (15.2\% women and $13.7 \%$ men), $13.9 \%$ dedicate between 26 and up to $50 \%$ of their income to paying debts (14.6\% women and $13.1 \%$ men) and $1.8 \%$ dedicate between $51 \%$ and up to $100 \%$ of their income to settling liabilities $(2.1 \%$ women and $0.7 \%$ men). None of the differences in distributions by gender were significant.

$62.6 \%$ of respondents in this sample had never had a credit card, and most of those who do, have at least 1 (194\%), $15.7 \%$ have up to 2 credit cards while $2.6 \%$ have between 3 and 5 (see Table 4). Even though in this distribution there were no significant differences based on gender, it is important to note that there are no considerable inequalities between having 1 credit card (the groups are tied starting from those who have 3 credit cards and going up), but rather in those that have no credit card.

The participants were also asked which aspect they consider the most important before deciding to use a credit card, and $50 \%$ of the sample stated "the interest rate" as a priority. $14.9 \%$ chose as the most important the credit line offered, $13.4 \%$ chose the fees, $6.7 \%$ the user protection and there was a tie, at $6.2 \%$ between the institution that offers the credit and the life insurance. $2.7 \%$ of them considered whether the credit was in minimum wages or in pesos as primordial. 
$63.5 \%$ of the sample answered correctly when asked what happened when delaying payment on a credit card ("you pay more interest"), and of this group, more than half were women (35.3\%). Nevertheless, women were also a majority in the group that gave other explanations on that topic (being harassed on the phone and threatened with house seizure was one of the most mentioned consequences), $6.7 \%$ of them being women.

$22 \%$ of the respondents received at some point a credit card they did not request. Of this group, $12.1 \%$ were women and $10.6 \%$ were men. Regarding the number of times they used their credit card in the last month before the survey, 231 people did it as follows: $16.9 \%$ had used it at least once $(10.8 \%$ women and $6.1 \%$ men), $16 \%$ had used it at least twice (5.2\% women, $10.8 \%$ men), $5.2 \%$ had used it three times (3.5\% women, $1,7 \%$ men), $1.7 \%$ had used it four times ( $1.3 \%$ women and $0.4 \%$ men) and $6 \%$ had used it between 5 and 15 times (of this group only $1.3 \%$ were women).

With regard to payment habits (see Table 5), 40\% claimed they paid all that was due when they received the charge (in banking jargon they are known as "totaleros", those that pay the total amount) and the gender distributions are very similar; in fact this is the only group that could be considered as having healthy financial habits, because as they pay in full they do not need to pay

Table 4. Credit cards by gender.

\begin{tabular}{cccc}
\hline \multirow{2}{*}{ Number of credit cards } & \multicolumn{3}{c}{ Percentage by gender } \\
\cline { 2 - 3 } & Total & Women & Men \\
\hline 1 & $62.6 \%$ & $36.5 \%$ & $26.1 \%$ \\
2 & $19.4 \%$ & $12.5 \%$ & $7.0 \%$ \\
3 & $15.7 \%$ & $5.5 \%$ & $10.1 \%$ \\
4 & $1.7 \%$ & $0.9 \%$ & $0.9 \%$ \\
5 & $0.3 \%$ & $0.3 \%$ & $0 \%$ \\
Total & $0.3 \%$ & $0 \%$ & $0.3 \%$ \\
\hline
\end{tabular}

Source: Compiled by the author based on results.

Table 5. Credit card payment by gender.

\begin{tabular}{cccc}
\hline \multirow{2}{*}{\begin{tabular}{c} 
When paying your credit card, you usually: \\
\cline { 2 - 3 } Pay the minimum amount
\end{tabular}} & \multicolumn{2}{c}{ Type of payment by gender } \\
\hline Pay more than the minimum amount & $21.7 \%$ & $11.7 \%$ & $10.0 \%$ \\
Pay all that is due & $30.0 \%$ & $20.8 \%$ & $9.2 \%$ \\
Pay what you can in that moment & $40.0 \%$ & $19.2 \%$ & $20.8 \%$ \\
If I don't have the minimum amount I don't pay & $1.7 \%$ & $3.3 \%$ & $3.3 \%$ \\
\hline
\end{tabular}

Source: Compiled by the author based on results. 
interests. They are followed by the group that usually "pays more than the minimum amount" and then those that pay "the minimum amount"; the difference between these groups was also statistically insignificant in terms of gender.

$15.9 \%$ of the sample also had an overdue payment at the time of the survey (9.3\% women and $6.7 \%$ men) and $3.2 \%$ "didn't know" (2.3\% women and $0.9 \%$ men), $32.2 \%$ claimed they had no overdue payment (18\% women and $14.2 \%$ men) while $48.7 \%$ said they had no credit cards or credit in force, so the question did not apply to them. In regard to the institution where they had obtained their credit, $14 \%$ of the general sample mentioned Bancomer, in the women's group there is a tie between Bancomer and HSBC, while in the men's group, 7.7\% mentioned Bancomer and 7\% HSBC.

When they need money for an emergency, $19.5 \%$ of women said they resort to their savings, $17.6 \%$ ask for loans and $6.1 \%$ sell some personal item to cover the emergency. $18.5 \%$ of men ask for a loan, $13.1 \%$ resort to their savings and $4.3 \%$ choose both options.

The majority of the samples (42.3\%) ask for a loan from their family. From this group, $25.8 \%$ are women and $16.5 \%$ are men. $14.8 \%$ resort to friends first $(7.9 \%$ women and $7 \%$ men) while $11 \%$ resort to a creditor (4.9\% women and $6.1 \%$ men), $9.9 \%$ go to an institution ( $4.6 \%$ women and $5.2 \%$ men) and $6.4 \%$ first evaluate all previously mentioned options ( $2.9 \%$ women and $3.5 \%$ men). $15.7 \%$ of respondents stated they do not ask for loans ( $9.6 \%$ women and $6.1 \%$ men).

In terms of the frequency with which they make purchases or have expenses that exceed their income, $1.5 \%$ ( $1.2 \%$ women and $0.2 \%$ men) of the sample said they "never" do it. $37.3 \%$ (21.8\% women and $15.5 \%$ men) said they "hardly ever" do it. $30.7 \%$ (18.8\% women and $111.9 \%$ men) said "rarely", 15.5\% (6.3\% women and $9.3 \%$ men $)$ do it "regularly". $12.8 \%$ (6.9\% women and $6 \%$ men) do it "somewhat frequently" while $2.1 \%$ ( $1.2 \%$ women and $0.9 \%$ men) state they do it "all the time". There was no significant difference in terms of gender.

An interesting aspect is what motivated the respondents to have unnecessary expenses or excessive debt: $40 \%$ said they did it "for fun or because they chose to" ( $20.6 \%$ women and $19.4 \%$ men), which shows that it is an impulse they were not able to control. $12.2 \%$ said "due to social influence or pressure" (5.2\% women and $7 \%$ men), which allows us to assume that some people are vulnerable to other people's opinions. Only $5.5 \%$ claimed to having done it "because of offers or sales" that they wanted to take advantage of in that moment. Of this last group, $3.5 \%$ are women and $2 \%$ are men. Although at first glance it may seem that women are usually more vulnerable or prone to wanting to take advantage of these situations, we would have to present each offer and sale in detail: one of the men asked stated that in the previous month he had purchased 3 tires for the price of 1 , although at that moment his car did not require a change of tires, and even though he had no place to keep them, and he was still missing one to be able to change all the tires of his vehicle.

Another of the important aspects while managing debt is to clearly distinguish the financial products and tools available. These vary depending on who grants 
the resource, both in institutions and in private loans done by creditors, or by family or friends. Getting information on the terms and conditions before using money that is not one's own should be a priority for both parts (institution/creditor and debtor). One may assume that at least in the legally established financial institutions this is what happens. In this study we asked participants if they had received counseling regarding the use and legal conditions when being given a credit card or some other type of loan.

The differences found were significant in terms of gender: generally, the group that answered "yes" was larger (57.9\%), and within this group, more than half were women $(30.2 \%)$. The proportion of men who claimed they had only been counseled for some of the credits was larger (18.2\%). Could this suggest that financial institutions focus more on women, trying to inform them before giving them a credit? Maybe not, because in the group of those who have not been counseled at all (37.1\%), more than half were also women (23.3\%). The significance test only mentions that there are significant differences in the groups compared but it does not explain the direction or the intensity of those differences.

Another aspect where significant differences were found in terms of gender is precisely the information and conceptualization that they have regarding a credit and a loan. They were asked if they knew what the differences were between the two, and the answers were as follows: $27.2 \%$ of the respondents consider that "only in the case of one of them you pay interests on the amount of the debt" ( $14.3 \%$ women and $13 \%$ men), $20 \%$ consider "there are no differences, both are debts" ( $12.8 \%$ women and $7.2 \%$ men); $13.9 \%$ consider that there are differences, "it depends on who gives it to you" (6.7\% women and $7.2 \%$ men); another $20.9 \%$ simply admitted they do not know (14.5\% women and $6.4 \%$ men) while $6.4 \%$ preferred not to answer the question ( $2 \%$ women and $4.3 \%$ men).

\subsection{Savings}

One of the most important aspects due to the social, economic and demographic context of the country and of the region being studied is without a doubt the savings. Although saving goes beyond merely accumulating money, since it starts with planning the expenses and the search for alternatives to stretch the available budget, in this section we will only focus on saving money.

$33.9 \%$ of the sample claimed they save money "sometimes, when they can" ( $21.4 \%$ women and $12.5 \%$ men), $32.5 \%$ said they save money "every time they receive their wage" ( $15.9 \%$ women and $16.5 \%$ men), $8.4 \%$ save money "at least once a month" (4.9\% women and 3.5\% men), 3.2\% stated they save "sometimes, when they want to" ( $1.7 \%$ women and $1.4 \%$ men) while $19.4 \%$ stated they did not save money (9.6\% women and $9.9 \%$ men).

Within the group of people who save money, there were differences when answering the question "What is your main reason for saving money?" 37.7\% said they do it for "goals and projects" (20\% women and 17.7. men), $34.2 \%$ mentioned they do it for "emergencies" (22\% women and $12.2 \%$ men), $7.8 \%$ said "for 
retirement" (3.8\% women and 4.1\% men), 3.5\% said "for several of the aforementioned" (2.6\% women and $0.9 \%$ men) and $2.6 \%$ for "other reasons" $(0.9 \%$ women and $1.7 \%$ men). In this last group, they mentioned their own professional education or that of their children, starting a business, going on vacation among others.

They were also asked if in their workplace they had some kind of savings program and $26.7 \%$ said they did (12.8\% women and $13.6 \%$ men), $49 \%$ said they didn't (27\% women and $22 \%$ men), $2 \%$ said they didn't know (1.4\% women and $0.6 \%$ men) and $22 \%$ considered the question did not apply to them because they were micro entrepreneurs or independent workers $(14.2 \%$ women and $7.8 \%$ men).

With respect to the percentage of their income that they assign to saving (see Table 6), of those that do save money, the largest group allocates between $10 \%$ and $25 \%$ of their income, followed by those who save between $26 \%$ and $50 \%$ and in third place by those that assign less than $10 \%$ of their income.

Despite the fact that the differences in these groups were not significant in statistical tests, it is worth mentioning that the proportion of women that do not save money is greater, but they were also the only ones in a strange group that assigns almost all their income to savings.

This being a geographic border area, the use of the dollar as daily currency is very common, and it is even more so when dealing with savings, since, because of the changes that the exchange rates of this currency with respect to the Mexican peso have gone through, it is commonly considered that saving in dollars helps you gain a few pesos when the first rises or the second falls. At the time of this survey, one dollar was worth between 13 and 14 pesos. A significant difference based on gender was found precisely in terms of the currency they usually save money in.

Although the majority of the respondent sample save in Mexican pesos, an important proportion do so in both currencies, while the smallest part do so exclusively in dollars (see Table 7). It is worth noting that women are a majority in the group that save in both currencies and in those that save only in pesos, but

Table 6. Percentage of income assigned to savings by gender.

\begin{tabular}{cccc}
\hline \multirow{2}{*}{\begin{tabular}{c} 
Percentage of the income assigned to savings \\
\cline { 2 - 3 } None
\end{tabular}} & Total & Women & Men \\
\hline Less than $10 \%$ & $33.0 \%$ & $35.4 \%$ & $30.1 \%$ \\
Between $10 \%$ and $25 \%$ & $5.5 \%$ & $7.3 \%$ & $3.3 \%$ \\
Between $26 \%$ and $50 \%$ & $38.0 \%$ & $37.0 \%$ & $39.2 \%$ \\
Between $51 \%$ and $75 \%$ & $18.0 \%$ & $15.6 \%$ & $20.9 \%$ \\
Between $76 \%$ and $95 \%$ & $4.3 \%$ & $2.6 \%$ & $6.5 \%$ \\
\hline
\end{tabular}

Source: Compiled by the author based on results. 
Table 7. Savings currency by gender.

\begin{tabular}{cccc}
\hline \multirow{2}{*}{ Currency } & \multicolumn{3}{c}{ Savings by gender } \\
\cline { 2 - 4 } & Total & Women & Men \\
\hline Mexican Pesos & $67.8 \%$ & $39.7 \%$ & $28.1 \%$ \\
American dollars & $5.8 \%$ & $1.4 \%$ & $4.3 \%$ \\
Both & $16.8 \%$ & $9.0 \%$ & $7.8 \%$ \\
Does not apply & $9.6 \%$ & $5.5 \%$ & $4.1 \%$ \\
\hline
\end{tabular}

Source: Compiled by the author based on results.

Table 8. Social influences on savings by gender*.

\begin{tabular}{cccc}
\hline \multirow{2}{*}{ Influences on saving } & \multicolumn{3}{c}{ Influences by gender } \\
\cline { 2 - 4 } & Total & Women & Men \\
\hline Father saved money & $49.5 \%$ & $28.4 \%$ & $21.1 \% \%$ \\
Mother saved money & $69.6 \%$ & $39.0 \%$ & $30.7 \%$ \\
Friends saved money & $21.7 \%$ & $11.2 \%$ & $10.5 \%$ \\
Partner/ former partner saved money & $24.3 \%$ & $13.1 \%$ & $11.2 \%$ \\
Grandparents saved money & $4.3 \%$ & $2.6 \%$ & $6.5 \%$ \\
Another person that raised them saved money & $3.5 \%$ & $1.3 \%$ & $2.2 \%$ \\
They told me about saving money in school & $46.3 \%$ & $26.8 \%$ & $19.5 \%$ \\
They told me about saving money at work & $29.4 \%$ & $14.1 \%$ & $15.3 \%$ \\
\hline
\end{tabular}

*Percentages and totals based on 313 respondents. Dichotomy group tabulated at a value of 1 . Source: Compiled by the author based on results.

they are also a majority in the group that state they do not save money (5.5\%). This last group, that denies saving money, has been growing smaller in proportion with respect to previous questions, which might indicate the fact that indeed these $9.6 \%$ (of the $33 \%$ who originally claimed they did not save money, see Table 6) are those who do not have savings.

Another one of the statistically significant findings in terms of gender is related to collective saving, known as "tandas". While only a small part of the sample use them (6.5\%) of that group, they were almost entirely women (5.2\%). In terms of the preference in using saving tools, $48.8 \%$ prefer saving in "bank accounts" (287\% women and $20.2 \%$ men), $41.7 \%$ prefer to use the traditional "piggy bank" ( $21.3 \%$ women and $20.4 \%$ men) and $8.6 \%$ prefer to save using a different tool ( $4 \%$ women and $4.6 \%$ men). In this last group they mentioned investment accounts, trusts and savings banks among others. In regards to social influences on saving (see Table 8) it was found that the maternal figure had the strongest impact on the general sample, and in this group, particularly on women. It is followed by the paternal figure where once again there are more women who stated they have felt its influence. In third place there is the school influence, and once again the majority of those affected were women. Then there is the workplace: even though it is an important influence, because it is where 
economically active adults spend the majority of their time outside the home, it was the men who were most influenced to save money, by their workplace or by their employer.

The relationship changes again when talking about the partner or former partner, where once again women were more influenced to save money. Friends, grandparents and other people within the group of people that the individuals were raised with also had a certain degree of influence on the participants, although none of the factors had statistical significance in the gender analysis.

A savings influence index was created based on this information, and the following distribution was observed: $9.3 \%$ had no influence to save money $(6.1 \%$ women and $3.2 \%$ men), $20 \%$ had at least one influence (10.7\% women and $9.3 \%$ men), $31.9 \%$ had two influences ( $17.7 \%$ women and $14.2 \%$ men), $19.4 \%$ had 3 influences (10.4\% women and $9 \%$ men), $11 \%$ had 4 influences (6.1\% women and $4.9 \%$ men), $4.6 \%$ had 5 influences (2.3\% women and $2.3 \%$ men), $2.3 \%$ had 6 influences ( $1.7 \%$ women and $0.6 \%$ men), $1.2 \%$ had up to 7 influences $(0.6 \%$ women and $0.6 \%$ men) while $0.3 \%$ had 8 influences to save money ( $0 \%$ women and $0.3 \%$ men).

\subsection{Expectations for the Future, Professional Education and Income}

Economic and financial literacy can be linked easily to these three aspects, when one considers the implicit variable "welfare" [7], and they are all based on long term planning, for which one must also consider opportunity costs. When the respondents were asked to mention their three main goals in life in order of priority, their answers allow us to see whether their vision is long term or short term. Even between prioritizing themselves or their financial dependents there is a difference, which although small, proved to be statistically significant for the gender analysis of the data.

The majority of the respondents (34.5\%) have "their own house" as a priority (19.5\% women and 15\% men), $23.6 \%$ prioritize "finishing their professional studies" ( $12.7 \%$ women and $10.9 \%$ men) followed by $22.4 \%$ whose priority is to "start a business" ( $12.7 \%$ women and $9.7 \%$ men) and then $20.9 \%$ who prioritize "that my children finish their studies".

In this last group, $15.3 \%$ are women and only $5.6 \%$ are men, and the statistical significance, at a level of confidence of $95 \%$ is 0.000 . This finding can be related to the data found for questions regarding expectations about professional education, where the gender differences were also significant: of the $61.6 \%$ of the sample who considered that "professional education helps to get a better job", $60.45 \%$ are women.

Positive expectations regarding future welfare that women have regarding education and especially professional education [7] are higher than those held by men: for this sample it was found that $8.1 \%$ of women consider that "it helps them work fewer hours", compared to $3.8 \%$ of men who consider the same thing; $11.3 \%$ of women consider "it helps them know more things", compared to 
$11 \%$ of men; $8.4 \%$ of women consider "it helps them live a less stressful life" compared to $6.1 \%$ of men who think the same way. Nevertheless, this concepts should not generate delusions, especially when talking about the opportunity to better oneself even without having a professional education: $14 \%$ of the respondents consider that "professional education helps manage money better", and in that group $73 \%$ are women.

It is not necessary to go to college to learn how to manage money. There are various institutions that offer free courses on that subject, there are face to face options and even online ones, but one should analyze not only the accessibility to travel in order to receive them, or the infrastructure and technological equipment necessary to take them online, but also the willingness that each individual has to do it. In that sense, when asked if they would like to receive free training on various economic and financial topics (they could select from a list the topics they were interested in), 76.5\% answered "no", and in that group 56\% were women.

\subsection{Influences on Economic Knowledge}

They were asked where they usually get their information on daily economic and financial aspects from, and the distribution is as follows: $30.4 \%$ of the respondents stay informed from newspapers (17.4\% women and 13\% men), $29.6 \%$ do so from the radio ( $17.1 \%$ women and $12.5 \%$ men), $64.9 \%$ do so from the television (38\% women and $27 \%$ men), $31.3 \%$ stay informed on the internet $(14.8 \%$ women and $16.5 \%$ men). It is worth mentioning that this tool was the only one that showed significant gender based differences. $18.8 \%$ stay informed from social networks (9.9\% women and $9 \%$ men), 13\% hear about these topics in schools $(6.7 \%$ women and $6.4 \%$ men $), 17.1 \%$ stay informed at work $(8.1 \%$ women and $9 \%$ men), $22.3 \%$ usually hear about these topics within the family ( $13.9 \%$ women and $8.4 \%$ men), $16.2 \%$ with friends ( $8.1 \%$ women and $8.1 \%$ men) and $6.1 \%$ stay informed or hear about these topics in other places $(3.2 \%$ women and $2.9 \%$ men).

\subsection{Income Inequalities}

Another of the findings with significant gender related differences was the income. Most of the respondents had an income ranging from 1001 to 1500 pesos per week, and women stand out as the majority in this range (see Table 9).

In the levels below this one, it is once again the sample of women who represent the majority in all those groups: in the first two, the variations go up to 3 percentage points but in the third range the difference increases to become almost 3 times larger.

In the ranges above the mode, there is once again a difference of around 3 percentage points, nevertheless in the income range between 2501 and 4000 pesos, the proportions are equal, only to double once again in the two upper income ranges, while in the uppermost range there is no female presence at all. 
Table 9. Weekly income range by gender.

\begin{tabular}{cccc}
\hline \multirow{2}{*}{ Approximate weekly income range in pesos } & \multicolumn{3}{c}{ Income by gender } \\
\cline { 2 - 4 } Zero & Total & Women & Men \\
\hline Less than 500 & $8.1 \%$ & $5.1 \%$ & $3.0 \%$ \\
$501-1000$ & $13.7 \%$ & $8.4 \%$ & $5.4 \%$ \\
1001 to 1500 & $22.1 \%$ & $15.8 \%$ & $6.3 \%$ \\
1501 to 2500 & $28.4 \%$ & $15.8 \%$ & $12.5 \%$ \\
2501 to 4000 & $16.1 \%$ & $6.6 \%$ & $9.6 \%$ \\
4001 to 5000 & $6.0 \%$ & $3.0 \%$ & $3.0 \%$ \\
5001 to 10,000 & $2.1 \%$ & $0.6 \%$ & $1.5 \%$ \\
More than 10,000 & $2.7 \%$ & $0.9 \%$ & $1.8 \%$ \\
\hline
\end{tabular}

Source: Compiled by the author based on results.

\section{Conclusions}

Examining the differences in economic culture by gender in a northwestern region of Mexico allows us to assess the role of the people as agents of economic power. The attitudes, habits and social influences that make up each person's context cannot be excluded from an analysis that seeks explanations to comprehend how individuals make decisions for each economic situation and aspect in their life. The notions they have are also an important part of their administrative analysis and processes, as they can be clear and congruent with reality, or erroneous and dysfunctional so as to represent, at a particular moment, personal barriers that can impede personal growth.

To Rawbow and Rodriguez (1993), the role of the working woman impacts not only herself, by endowing herself with power, but also part of that power can be a factor of generational impact, provided that the influences can be considered positive, be it in the making of correct decisions or in the learning from those that were not correct.

For the case of this analysis, although no significant gender differences were observed in all the aspects that were believed to have such differences, such as the attitudes regarding purchases, savings, expenses and the use of credit, as in the findings of Denegri \& Palavecinos [1], Atkinson \& Messi [4], Falahati \& Sabri [7], and without minimizing those that did have differences, women are an agent of power and influence on others, mostly on their sons, and especially on their daughters.

Women having the adequate image of their own power could be the missing impulse in order to be able to compete in aspects where there is still a confirmed classical gender difference in economic culture: income inequality. But in such a case, other limitations to overcoming this barrier may arise in future more in depth analyses, such as being a single mother (or widow, divorced or separated).

With respect to the present brief comparison, the groups of men and women 
did not really show significant differences regarding all the other aspects. Even so, we still do not have evidence to state that there is no gender inequality, at least not in terms of general economic behaviors, attitudes and habits.

\section{References}

[1] Denegri, M. and Palavecinos, M. (2003) Gender and Economic Literacy: Opportunities for Development or New Paths for Discrimination? Psicología desde el Caribe, 76-97. http://www.redalyc.org/pdf/213/21301206.pdf

[2] Swarnankur, C. (2013) Borrowing Decisions of Credit Constrained Consumers and The Role of Financial Literacy. Economics Bulletin, 33, 179-191.

[3] Diez-Martínez, E. (2009) Socioeconomic and Financial Literacy and Financial Education for Sustainable Consumption in Mexico: Some Reflections from Psychology and Education. CPU-e, Journal of Educational Research, 8, 1-15. http://www.redalyc.org/pdf/2831/283121717005.pdf

[4] Atkinson, A. and Messy, F. (2012) Measuring Financial Literacy: Results of the OECD/International Network on Financial Education (INFE) Pilot Study. OECD Working Papers on Finance, Insurance and Private Pensions, No. 15, OECD Publishing.

http://www.oecd-ilibrary.org/finance-and-investment/measuring-financial-literacy_ 5k9csfs90fr4-en

[5] Lusardi, A. and Mitchell, O. (2008) Planning and Financial Literacy: How Do Women Fare? American Economic Review, 98, 413-417.

https://www.aeaweb.org/articles?id=10.1257/aer.98.2.413 https://doi.org/10.1257/aer.98.2.413

[6] Lusardi, A. and Tufano, P. (2009) Debt Literacy, Financial Experiences and Overindebtedness, National Bureau of Economic Research, NBER Working Paper Series, Working Paper No. 4808.

http://www.dartmouth.edu/ alusardi/Papers/Lusardi_Tufano.pdf

[7] Falahati, L. and Sabri, F. (2015) An Exploratory Study of Personal Financial Wellbeing Determinants: Examining the Moderating Effect of Gender. Asian Social Science, 11, 33-42. https://doi.org/10.5539/ass.v11n4p33 http://www.ccsenet.org/journal/index.php/ass/article/view/44260/24085

[8] Banamex (2014) Financial Culture of Young People in Mexico Summary of Results. Banamex Financial Education, National Bank of Mexico, Grupo Financiero Banamex.

http://www.banamex.com/es/conoce_banamex/quienes_somos/prensa/pdf/book_br ujula_digital_2014.pdf

[9] Mexican Council of Economic and Financial Education (CMEF) (2014) Economic and Financial Education for Life. http://www.cmeef.org.mx

[10] Ministry of Public Education (SEP) (2009) Notebook of Strategies for the Economic and Financial Training. Ministry of Public Education, Mexico.

[11] Rawbow, J. and Rodríguez, K. (1993) Socialization toward Money in Latino Families: An Exploratory Study of Gender Differences. Hispanic Journal of Behavioral Science, 3, 324-341.

http://journals.sagepub.com/doi/abs/10.1177/07399863930153003

https://doi.org/10.1177/07399863930153003 